\section{Н.А. Потапова}

Безработица в СССР в 1920-е годы: идеологическая доктрина и экономическая реальность

doi:10.31518/2618-9100-2021-6-11

УДК 94(47)

Выходные данные для цитирования:

Потапова Н.А. Безработица в СССР в 1920-е годы: идеологическая доктрина и экономическая реальность // Исторический курьер. 2021. № 6 (20). C. 134-141. URL: http://istkurier.ru/data/2021/ ISTKURIER-2021-6-11.pdf
N.A. Potapova*

\section{Unemployment in the Soviet State in the 1920s: Ideological Doctrine and Economic Reality}

\author{
doi:10.31518/2618-9100-2021-6-11
}

How to cite:

Potapova N.A. Unemployment in the Soviet State in the 1920s: Ideological Doctrine and Economic Reality // Historical Courier, 2021, No. 6 (20), pp. 134-141. [Available online: http://istkurier.ru/ data/2021/ISTKURIER-2021-6-11.pdf]

Abstract. Unemployment arises at the turn of the $20^{\text {th }}$ century in Russia. According to the 1913 population census, carried out only in a number of large cities of the country, about 500 thousand people were recorded who did not have any means of subsistence due to the lack of permanent work. The World War, the subsequent revolutionary events, the first economic transformations of the new government provoked a massive influx of rural residents into the cities. The increase in the urban population occurred against the background of a lack of jobs due to insufficient growth in industrial production. Therefore, the Soviet leadership already in 1921 faced the problem the existence of a massive and growing reserve army of labor. By the spring of 1927, there were about 1.5 million unemployed in the USSR. The real economic picture did not correspond to the ideological doctrine of the Bolsheviks, which admitted the existence of unemployment only in the capitalist social order. On the contrary, in the socialist system, the continuous growth of production is accompanied by a constant increase in the number of workers, which leads to full employment of citizens. Therefore, the Soviet government in the early 1920s embarked on a course of elimination of unemployment. The article analyzes the measures taken in the fight against unemployment of the population, on the basis of which three stages of the state policy of destroying the "heritage of capitalism" can be distinguished. The first stage dates back to the period 1918-1921, when an attempt was made to destroy the free labor market, the existence of which was contrary to socialist ideas. However, the introduction of the NEP not only marked the beginning of the next period, but also suspended the policy of strict regulation in this area. In 1927, the third stage began, marked by a return to the system of planned construction of the national economy, regulation of the labor market, organized supply of industry, etc. The result of these transformations was the closure of labor exchanges in 1930, the termination of preferential payments, and at the beginning of 1931 the USSR declared itself the first country in the world to defeat unemployment, despite the fact that since 1927 labor exchanges had been carrying out the so-called purges, striking off the register thousands thousands of people, depriving them of their right to work. Based on this, the author casts doubt on the conclusion that was fixed in Soviet historiography about the elimination of unemployment in the USSR and makes the assumption that unemployment after 1930 changed the form of its existence.

Keywords: NEP; unemployment; labor exchange; unemployed population; government measures; industrialization.

The article has been received by the editor on 04.11.2021.

Full text of the article in Russian and references in English are available below.

\footnotetext{
* Потапова Наталья Анатольевна, кандидат исторических наук, Институт истории Сибирского отделения Российской академии наук, Новосибирск, Россия, e-mail: skna17talya@mail.ru

Potapova Natalia Anatolievna, Candidate of Historical Sciences, Institute of History of the Siberian Branch of the Russian Academy of Sciences, Novosibirsk, Russia, e-mail: skna17talya@mail.ru
} 
Аннотация. Безработица в России возникает на рубеже XIX-XX вв. Согласно переписи населения 1913 г., проведенной только в ряде крупных городов страны, было зафиксировано около 500 тыс. чел., не имевших никаких средств к существованию вследствие отсутствия постоянной работы. Мировая война, последующие революционные события, первые экономические преобразования новой власти спровоцировали массовый приток сельских жителей в города. Увеличение городского населения происходило на фоне отсутствия рабочих мест вследствие недостаточного роста промышленного производства. Поэтому советское руководство уже в 1921 г. столкнулось с проблемой существования массовой и растущей резервной армии труда. К весне 1927 г. в СССР насчитывалось около 1,5 млн незанятых. Реальная экономическая картина не соответствовала идеологической доктрине большевиков, которая допускала наличие безработицы только в капиталистическом общественном строю. Напротив, в социалистической системе непрерывный рост производства сопровождается постоянным увеличением численности работающих, что ведет к полному трудоустройству граждан. Поэтому советской властью в начале $1920-$ х гг. был взят курс на ликвидацию безработицы. В статье анализируются принятые меры в борьбе с незанятостью населения, на основании которых можно выделить три этапа государственной политики уничтожения «наследия капитализма». Первый этап датируется периодом 1918-1921 гг., в это время была предпринята попытка разрушить свободный рынок труда, существование которого противоречило социалистическим идеям. Однако введение нэпа не только ознаменовало начало следующего периода, но и приостановило политику жесткого регулирования в экономической сфере. С 1927 г. начинается третий этап, ознаменовавшийся возвращением к системе плановости строительства народного хозяйства, регулирования рынка труда, организованного снабжения промышленности и т.д. Итогом этих преобразований стало закрытие бирж труда в 1930 г., прекращения льготных выплат, а в начале 1931 г. СССР объявил себя первой страной в мире, победившей безработицу. Однако с 1927 г. биржи труда проводили так называемые чистки, снимая со своего учета тысячи людей, лишая их права на труд. На основании этого автор ставит под сомнение закрепившийся в советской историографии вывод о ликвидации незанятости населения в СССР и делает предположение о том, что безработица после 1930 г. изменила форму своего существования.

Ключевые слова: нэп; безработица; биржа труда; незанятое население; государственные меры; индустриализация.

Советская идеология определяла безработицу как «явление, присущее капиталистическому общественному строю, когда часть трудящихся не может найти себе работу, становясь “излишним” населением, резервной армией труда» ${ }^{1}$. Напротив, при социалистической системе безработица отсутствует, так как непрерывный рост производства сопровождается постоянным увеличением численности работающих, что, в свою очередь, ведет к полной занятости населения. Однако несмотря на идеологические доктрины, уже в 1921 г. большевистское руководство столкнулось с масштабным и стремительным ростом незанятого населения.

Мировая война, последующие революционные события, первые экономические преобразования новой власти спровоцировали массовый приток сельских жителей в города. Увеличение городского населения происходило на фоне отсутствия рабочих мест вследствие недостаточного роста промышленного производства. Кроме того, экономическая обстановка 1920-х гг., нехватка денежных средств возродили в крестьянской среде практику временного ухода с постоянного места жительства в города с целью заработка, что также негативно сказывалось на общей картине. Помимо уже перечисленных причин безработицы, ряды нетрудоустроенных пополняли демобилизованные красноармейцы. Иначе говоря, реальная картина, сложившаяся в результате революционных трансформаций, не совпадала с совет-

\footnotetext{
${ }^{1}$ Большая советская энциклопедия: [в 66 т.].1-е изд. М.: 1926-1947. БСЭ. Т. 5. 1927. Стлб. 209-248.
} 
скими идеологическими установками. Поэтому на протяжении всех 1920-х гг. руководство страны вело борьбу с позорным «наследием капитализма», трансформируя экономическую, политическую и социальную сферы. Итогом преобразований стало закрытие в 1930 г. в Москве последней в стране биржи труда, а в начале 1931 г. постановление ЦИК СССР заявило о том, что Советский Союз стал первым государством, победившим безработицу ${ }^{2}$, хотя пятилетний план намечал сокращение числа незанятого населения до 400 тыс. Подводя итоги первому этапу индустриализации, И.В. Сталин констатировал: «Одно из основных завоеваний пятилетки в четыре года состоит в том, что мы уничтожили безработицу и избавили рабочих СССР от ее ужасов» ${ }^{3}$.

Важное мероприятие на рынке труда было сделано еще в начале 1918 г., которое задавало вектор экономического развития социалистического государства на ближайшее деся тилетие. Январский декрет СНК «О биржах труда» закрывал все частные и платные бюро и конторы по найму, взамен вводил государственные биржи труда, в функции которых входило трудоустройство безработных, выдача им пособий, учет и распределение рабочих во всех отраслях народного хозяйства, а также упорядочение спроса и предложения труда, организации общественных работ и т.д. ${ }^{4}$ Теперь безработные обязывались вставать на учет бирж, которые выступали посредником между нанимателем и работником, не прошедшие процедуру регистрации не только не могли быть приняты на работу, но и не имели права претендовать на пособия и другие льготы по безработице. Фактически этот декрет стал первым шагом в деле уничтожения свободного рынка труда, так как существование последнего противоречило социалистическим идеям.

С введением нэпа руководство страны ослабило политику жесткого регулирования рынка труда. В первой половине 1920-х гг. население, не опасаясь государственных санкций, могло обходить биржи труда при найме на работу, предоставлять частные услуги с целью заработка и т.д. Однако уже в январе 1928 г. народный комиссар труда В.В. Шмидт в своем докладе отмечал, что сложившаяся в СССР система регулирования находится в явном противоречии с системой плановости строительства народного хозяйства ${ }^{5}$. Для исправления сложившейся ситуации нарком в ближайшее время планировал вернуться к плановости регулирования рынка труда, организованному снабжению промышленности, регулированию отходничества, перераспределению излишков рабочей силы. Кроме того, намеревались провести чистку бирж труда с целью снять с учета всех неквалифицированных лиц, а также принять меры по усилению дисциплины среди незанятого населения. Это заявление, ставшее программой преобразований рынка труда в ближайшие годы, было сделано на фоне чрезвычайно сложной экономической ситуации. Безработица в стране росла резкими темпами, за период 1921-1927 гг. численность населения без средств к существованию выросла в пятнадцать раз.

По данным ЦСУ (Центральное статистическое управление), к концу 1921 г. в стране на учете бирж труда находилось 100 тыс. чел., к 1 января 1923 г. эта цифра увеличилась до 641 тыс. чел., а к началу 1924 г. уже 1240 тыс. чел. не имели постоянной работы ${ }^{6}$, т.е. за два года количество нетрудоустроенных возросло почти в 12,5 раза. Во второй половине 1920-х гг. положение еще более обострилось, к весне 1927 г. около 1,5 млн чел. оказались без средств к существованию. Основной удар пришелся на РСФСР, доля неработающего населения в республике составляла около 46,8 \%. Особенно затяжной и застойный характер безработица носила среди лиц неквалифицированного $(44,3$ \%) и интеллигентного $(25,1 \%)$ труда, а также среди женщин (47,5 \%) и подростков $(12,2 \%)^{7}$.

\footnotetext{
${ }^{2}$ Решения партии и правительства по хозяйственным вопросам. 1917-1967 гг.: сб. док-тов за 50 лет. М., 1967. Т. 2: 1929-1940 гг. С. 250-254.

${ }^{3}$ Сталин И.В. Вопросы ленинизма. Изд. 10-е. М., 1938.

${ }^{4}$ Собрание узаконений и распоряжений правительства за 1917-1918 гг. Управление делами Совнаркома СССР. М., 1942. С. 322-323.

${ }^{5}$ Индустриализация СССР 1926-1928 гг.: док-ты и мат-лы. М., 1969. С. 350-366.

${ }^{6}$ Рогачевская Л.С. Ликвидация безработицы в СССР 1917-1930 гг. М., 1973. С. 76-77.

${ }^{7}$ Государственный архив Новосибирской области (ГАНО). Ф. Р-532. Оп. 1. Д. 1033. Л. 21.
} 
В наиболее трудной обстановке оказались чернорабочие. В докладах НКТ отмечалось, что дальнейшие индустриальные процессы вызовут смягчение безработицы только среди квалифицированных групп. Так, например, в 1925-1926 гг. для удовлетворения спроса советской промышленности потребовалось всего 433 тыс. новых кадров, две трети из которых были специалистами ${ }^{8}$. Сокращению числа незанятых среди неквалифицированных рук препятствовал приток отходников, предложения труда со стороны подростков и демобилизованных советских служащих, которые зачастую не имели профессии, но обладали правом безочередного устройства на предприятие. Кроме того, конкуренцию вольнонаемному населению составлял труд заключенных, который использовался в промышленности на фоне тяжелой безработицы ${ }^{9}$.

Численные показатели требовали от партии принятия незамедлительных мер, направленных на перераспределение кадров. Первый шаг в этом направлении был сделан в феврале 1927 г. НКТ издал циркулярное письмо, которое запрещало безработным прибывать в Москву, Ленинград, Ярославль, Псков, Симферополь, Севастополь, Феодосию, Керчь, Фрунзе, Кзыл-Орду, Минск, Витебск, Бобруйск, Борисов, Могилев, Харьков, Одессу, Киев, Николаев, Днепропетровск, Запорожье, Баку, Тифлис, Самарканд, Ташкент, Бухару, Коканд, Хиву, Душанбе, Полторацк, Керки, Ленинск, Мерв, Ташауз ${ }^{10}$. В этих советских городах ситуация носила застойный характер.

С целью организованного снабжения промышленности в марте 1927 г. СНК СССР подписывает постановление «О мерах по регулированию рынка труда» ${ }^{11}$, согласно которому все государственные, общественные и частные предприятия обязывались заключать специальные соглашения с НКТ или территориальными отделами труда. Новые правила предусматривали набор кадров либо непосредственно нанимателем, либо биржами труда. Кроме того, накладывался запрет на привлечение людей из других местностей через использование посредников, не получивших полномочий, также воспрещалось вызывать работников при помощи писем и публикаций. Иными словами, только официально учтенное население могло рассчитывать на трудоустройство.

Однако данное постановление не учитывало того факта, что в Советском Союзе существовал недостаток бирж труда. Так, в 1924-1925 гг. в стране имелось 384 пункта, а уже в период 1926-1927 гг. - 250, т.е. сеть органов трудового посредничества не охватывала не только многие уездные города, но и промышленные центры ${ }^{12}$. Не вызывает сомнения, что при таком количестве бирж труда не все желающие могли встать на учет, а значит - найти работу. Но существовала и другая сторона, когда спрос на труд не мог быть удовлетворен. Так, например, в июле-сентябре 1927 г. сибирские биржи имели от предприятий запрос на 28735 чел., однако промышленность не смогла получить 3063 чел. (или 10,6 \%). Причин, объясняющих сложившуюся ситуацию, можно выделить несколько, а именно: отсутствие кадров необходимой квалификации (44,5\%), отказ от работы, где требовался переезд в другой регион (15,4 \%), низкооплачиваемый труд (10,1 \%), тяжелые условия $\left(6,3\right.$ \%) и пр. ${ }^{13}$

Начиная с 1927 г. НКТ стал постепенно вводить в практику санкционные меры в отношении тех, кто уклонялся от предлагаемого места. С этого времени биржи труда снимали с учета при следующих обстоятельствах:

- отказ от работы не по специальности;

- отказ от общественных работ;

- отказ от работы в коллективах безработных;

\footnotetext{
${ }^{8}$ ГАНО. Ф. Р-532. Оп. 1. Д. 1033. Л. 21.

${ }^{9}$ ГАНО. Ф. Р-532. Оп. 1. Д. 1176. Л. 19-20.

${ }^{10}$ ГАНО. Ф. Р-532. Оп. 1. Д. 103За. Л. 179-182.

${ }^{11}$ ГАНО. Ф. Р-532. ОП. 1. Д. 1379. Л. 44-47.

${ }^{12}$ Индустриализация СССР... С. 359.

${ }^{13}$ ГАНО. Ф. Р-532. Оп. 1. Д. 1176. Л. 5.
} 
- отказ одиноких людей, в особенности умственного труда (медицинских работников, просвещенцев, инженеров, техников и др.), от работы, требующей переезда на другое место жительство;

- отказ от работы, требующей переезда на другое место жительство, малосемейных в тех случаях, когда на новом месте предоставлялось жилье ${ }^{14}$.

Отказ в регистрации означал, помимо прекращения выплат пособий и отмены льгот, невозможность найти место работы со всеми вытекающими последствиями. Кроме того, с этого же времени к регистрации допускались только члены профсоюзов, а также имеющие специальность, трудовой стаж, дети рабочих и служащих, лица, окончившие высшие и средние учебные заведения ${ }^{15}$. В дальнейшие годы список людей, попадавших под такую меру воздействия, расширялся. Так, постановление НКТ СССР от 13 июля 1929 г. № 224 запрещало помогать в трудоустройстве не только лишенным избирательных прав, но и лицам, проживающим на иждивении лишенных избирательных прав ${ }^{16}$. В результате на рубеже 1920-1930-х гг. советское руководство при помощи санкционной политики подкорректировало цифры незанятого населения в стране. На данном этапе исследования трудно судить о численности лиц, подвергшихся таким мерам в общесоюзном масштабе. Но с уверенностью можно сказать, что по всей стране регистрацию потеряли тысячи человек. Так, например, Новосибирская биржа труда только в мае 1929 г. сняла с учета свыше 1 тыс. человек. В Омске в августе 1929 г. под санкции попали 1255 чернорабочих, в Томске $2060^{17}$. Принятые меры позволили существенно сократить численность учтенных безработных в СССР в период 1927-1931 гг., а людей, снятых с регистрации, лишить права на труд, так как в тех условиях найти работу в обход бирж труда стало невозможным.

Первая пятилетка, как и прогнозировалось руководством страны, существенно изменила ситуацию на рынке труда. Уже в 1928/1929 хозяйственном году предложение труда составило 124 тыс. чел., тогда как спрос превысил 209 тыс. чел. ${ }^{18}$ Однако наряду с этим на биржах труда продолжали находиться безработные, систематически отказывавшиеся от предложенной работы или переквалификации и которые подлежали снятию с учета. В постановлении союзного Наркомата труда (апрель 1929 г.) такая ситуация, при которой «стихийность рынка труда и найма рабочей силы противоречит задачам планового обеспечения промышленности рабочей силой», признавалась ненормальной ${ }^{19}$. Государство в условиях повышенного спроса на труд стало все чаще и чаще прибегать к принуждению. Так, в Иркутске отказ от выполнения ряда срочных сезонных работ, таких как прокладка Тулуновского железнодорожного участка, ремонт Култукского тракта, разгрузка в Автопромторге, привели к изданию местным окрисполкомом специального постановления от 2 сентября 1929 г., которое вводило обязательную трудовую повинность для всех состоящих на учете бирж труда неквалифицированных рабочих ${ }^{20}$.

Незанятость населения порождала массу проблем, в том числе материально-бытовых, финансовых и т.д. Еще в начале 1925 г. статья в газете «Правда» обвиняла безработицу в нищенском существовании советского населения ${ }^{21}$. Отсутствие работы, денег, жилья стало главной причиной увеличения в стране показателей преступности и самоубийств ${ }^{22}$. СССР захлестнула волна хулиганства. Согласно сведениям статистического отдела НКВД, на

\footnotetext{
${ }^{14}$ ГАНО. Ф. Р-532. Оп. 1. Д. 1481. Л. 2.

${ }^{15}$ Соколов А.К. Советская политика в области мотивации и стимулирования труда (1917 - середина 1930-х гг.) // Экономическая история. Обозрение. М., 2000. Вып. 4. С. 39-80.

${ }^{16}$ ГАНО. Ф. Р-532. Оп. 1. Д. 1512. Л. 61.

${ }^{17}$ ГАНО. Ф. Р-532. Оп. 1. Д. 1513. Л. 35-45.

${ }^{18}$ Сибирский край. Статистический справочник. Новосибирск, 1930. С. 425.

${ }^{19}$ Кузнецов А. Вопросы организации труда в 1931 году // Вопросы труда на новом этапе: сб. статей. М.; Л., 1931. C. 86.

${ }^{20}$ ГАНО. Ф. Р-532. Оп. 1. Д. 1513. Л. 35-45.

${ }^{21}$ Правда. 1925. 9 января.

${ }^{22}$ Гиндин Я.И. Новые формы работы бирж труда (с приложением постановлений и распоряжений Наркомтруда СССР о реорганизации Бирж труда). М., 1924. С. 11.
} 
10 тыс. чел. в РСФСР приходилось в 1925 г. - 3,2, в 1926 - 16,7, а в 1927 - 25,2 случая зарегистрированных противоправных действий, рассматривавшихся как преступные ${ }^{23}$. С другой стороны, проводимые советской властью мероприятия на рынке труда, застойный характер безработицы и сопутствующие тяжелые условия существования на почве материальной необеспеченности, наличие продовольственных затруднений способствовали нарастанию недовольства и распространению антисоветских настроений. Органы ОГПУ фиксировали, что особую опасность представляли биржи труда, так как здесь ежедневно концентрировалось большое скопление незанятых озлобленных масс.

Довольно острый характер ситуация носила в отдельных областях Украины, Закавказья, Казахстана. Безработица провоцировала межнациональное обострение межнациональных конфликтов в регионах с многонациональным составом проживающего населения. Согласно сводкам ОГПУ, в этих местах имело место быть распространение в массовых масштабах листовок антисоветского, националистического, русофобского характера. В этих пропагандистских материалах содержались призывы к свержению советской власти. Так, например, в Донбассе была создана «Украинская коммунистическая партия», которая среди рабочих проводила антисоветскую работу и пыталась внушить шахтерам, что причиной роста безработицы на Украине является политика большевистского правительства, которое закупает уголь в Англии, в то время как свой уголь не находит сбыта внутри страны. А в Казахстане в 1927 г. массовое и хорошо организованное выступление безработных потребовало привлечения регулярной армии для разгона бастующих ${ }^{24}$.

Сибирские чекисты отмечали, что эмоции незанятого населения особенно обострены. Подавленность, граничащая с отчаянием, приводит к господству погромных настроений, порождает призывы к беспорядкам. Особую опасность, по мнению сотрудников ОГПУ, представлял массовый и резкий характер недовольств, а также острые выпады против советской власти, партии и коммунистов. Так, например, в сводке ОГПУ за май 1929 г. были приведены следующие взгляды на сложившуюся экономическую ситуацию одной из безработных: «Скоро год, как без работы и не на один день никуда Биржа не посылала. Комиссия обследовала, сижу голодом, все имущество на себе, а на работу не посылают - говорят, не член союза, а где я вступлю в союз, когда мне 19 лет, училась в школе, а потом временно шила у кустаря. Говорят, с проституцией нужно бороться, а сами до этого доводят. Матери 70 лет, получает 8 руб. пенсии, на нем живем двое. Это называется молодежи дорогу даю, дают, но только не к труду, а к проституции, свобода не к жизни, а к голодной смерти» ${ }^{25}$.

Большие претензии предъявлялись к работе бирж труда: «Кумовство и протекционизм как были, так и остались. Очередь при посылке на работу биржа нарушает. Те, кто уволился позднее, давно уже получили работы, а мы все ждем». Обычным явлением стали выступления на биржах труда с требованием предоставить/отправить на работы, зачастую такие ультиматумы сопровождались драками с представителями власти, в частности с милицией: «Вот видите, какая нас масса безработных, и с каждым днем все больше и больше. Что они, большевики, нам дали? Только все время крестьян обирают. Сулили рай, а что дали? Скорее бы война, тогда они узнают, кто за нас пойдет» ${ }^{26}$. О массовости недовольств говорят цифры по пяти городам Сибирского края в мае 1929 г. В Омске, Новосибирске, Иркутске, Барнауле и Бийске было зафиксировано 307 актов выступлений безработных. Власти реагировали на это при помощи снятия с учета зачинщиков и участников волнений ${ }^{27}$. Также ответом со стороны советского руководства стали предложения о разгрузке бирж труда от безработных в целом, а в первую очередь антисоветских и хулиганствующих элементов.

\footnotetext{
${ }^{23}$ Статистический обзор деятельности местных административных органов НКВД. М., 1925. Вып. 4-5; М., 1926. Вып. 6; М., 1927. Вып. 7.

${ }^{24}$ Богданов С.В., Ельчанинов П.М. Безработица и социальный протест в Советской России в период НЭПа // Исторические, философские, политические и юридические науки, культурология и искусствоведение. Вопросы истории и практики. 2016. № 9 (71). С. 24-26.

${ }^{25}$ ГАНО. Ф. Р-532. Оп. 1. Д. 1513. Л. 35-45.

${ }^{26}$ ГАНО. Ф. Р-532. Оп. 1. Д. 1391. Л. 54-63.

27 Там же. Л. 28.
} 
Кроме того, продолжавшиеся выступления безработных спровоцировали поступление предложений о ликвидации бирж труда как места сосредоточения и объединения антисоветских настроений. Вероятно, это имело силу, так как постановлением «О немедленном направлении безработных на работу и о прекращении выплаты им денежной помощи», изданном в октябре 1930 г., отменялся статус безработного, а биржи труда из органов, выполняющих посреднические функции, превращались в планово-экономические управления по снабжению и подготовке рабочей силы. Вместо Комитета по борьбе с безработицей был образован Совет подготовки и поставки рабочей силы ${ }^{28}$.

Таким образом, в советской политике в борьбе с безработицей в 1920-е гг. можно выделить три этапа. Первый начинается в 1918 г. с принятия декрета «О биржах труда», который создал основу для жесткого государственного регулирования рынка труда. От идеи плановости экономики большевикам пришлось отступить в 1921 г. с введением нэпа. Период 1921-1927 гг. ознаменовался ослаблением контроля в экономической сфере. Однако именно в это время начался масштабный рост безработицы. К 1927 г. в стране на учетах бирж труда стояло около 1,5 млн человек. С 1927 г. начинается третий этап, ознаменовавшийся возвращением к системе плановости строительства народного хозяйства, регулированию рынка труда, организованного снабжения промышленности и т.д. В это же время в отношении незанятого населения, отказывавшегося по каким-либо причинам от предлагаемого места, стали применяться санкции, а именно: снятие с учета бирж труда, прекращение льготных выплат. Список лиц, попадающих под новые меры, постепенно расширялся. А в партийных документах 1929 г. имели место быть требования о разгрузке биржи труда. Борьба, направленная на ликвидацию последних, была связана с массовым скоплением здесь незанятого населения, настроенного против советской власти, открыто заявлявшего о борьбе с коммунистами. Частые драки и антиправительственные выступления требовали вмешательства органов власти. На рубеже 1920-1930-х гг. идеи о ликвидации бирж труда стали реальностью. Вероятно, скопление в этих местах антисоветски настроенных групп стало одной из причин закрытия в 1930 г. бирж труда. Поэтому, принимая во внимание ситуацию на рынке труда в конце 1920-х - начале 1930-х гг., вывод о ликвидации безработицы в СССР становится неочевидным. Вероятно, объявление о победе над «наследием капитализма» имело идеологический характер, а безработица после 1930 г. изменила форму своего существования.

\section{Лumepamypa}

Богданов С.В., Ельчанинов П.М. Безработица и социальный протест в Советской России в период НЭПа // Исторические, философские, политические и юридические науки, культурология и искусствоведение. Вопросы истории и практики. 2016. № 9 (71). С. 24-26.

Большая советская энциклопедия: [в 66 т.] / гл. ред. О.Ю. Шмидт. 1-е изд. М.: Советская энциклопедия, 1926-1947.

Гиндин Я.И. Новые формы работы бирж труда (с приложением постановлений и распоряжений Наркомтруда СССР о реорганизации Бирж труда). М.: Госиздат, 1924. 88 с.

Индустриализация СССР 1926-1928 гг.: док-ты и мат-лы. М.: Наука, 1969. 533 с.

Кузнецов А. Вопросы организации труда в 1931 году // Вопросы труда на новом этапе: сб. ст. М.; Л., 1931. 163 с.

Решения партии и правительства по хозяйственным вопросам. 1917-1967 гг.: сб. док-тов за 50 лет. М.: Политиздат, 1967. Т. 2. 1929-1940 гг. С. 250-254.

Сибирский край. Статистический справочник. Новосибирск, 1930. 804 с.

Соколов А.К. Советская политика в области мотивации и стимулирования труда (1917 середина 1930-х гг.) // Экономическая история. Обозрение. М.: Изд-во Московского ун-та, 2000. Вып. 4. С. 39-80.

\footnotetext{
${ }^{28}$ Угланов Н. Рост кадров рабочего класса, изжитие безработицы и снабжение социалистического строительства рабочей силой // Труд в СССР: сб. ст. к XVI парт. съезду. М., 1930. С. 65-68.
} 
Статистический обзор деятельности местных административных органов НКВД. М., 1925. Вып. 4-5; М., 1926. Вып. 6; М., 1927. Вып. 7.

Статистический обзор деятельности местных административных органов НКВД. М., 1926. Вып. 6; М., 1927. Вып. 7.

Статистический обзор деятельности местных административных органов НКВД. М., 1927. Вып. 7.

Угланов Н. Рост кадров рабочего класса, изжитие безработицы и снабжение социалистического строительства рабочей силой // Труд в СССР: сб. ст. к XVI парт. съезду / Наркомат труда СССР. М.: Гострудиздат, 1930. 183 с.

\section{References}

Bogdanov, S.V., Elchaninov, P.M. (2016). Bezrabotitsa i socialnyy protest v Sovetskoy Rossii v period NEPa [Unemployment and Social Protest in Soviet Russia During the NEP Period]. In Istoricheskie, filosofskie, politicheskie i yuridicheskie nauki, kul'turologiya i iskusstvovedenie. Voprosy istorii i praktiki. No. 9 (71), pp. 24-26.

Gindin, Ya.I. (1924). Novye formy raboty birzh truda (s prilozheniem postanovleniy i rasporyazheniy Narkomtruda SSSR o reorganizatsii Birzh truda) [New Forms of Work of Labor Exchanges (with the Attachment of Resolutions and Orders of the USSR People's Commissariat of Labor on the Reorganization of Labor Exchanges)]. Moscow, Gosizdat. 88 p.

Kim, M.P. (Ed.). (1969). Industrializatsiya SSSR 1926-1928. Dokumenty i materialy [Industrialization of the USSR 1926-1928. Documents and Materials]. Moscow, Nauka. 533 p.

Kuznecov, A. (1931). Voprosy organizatsii truda v 1931 godu [Questions of the Organization of Labor in 1931]. In Voprosy truda na novom etape: sb. statey. Moscow, St. Petersburg. 163 p.

(1967). Resheniya partii i pravitel'stva po hozyaystvennym voprosam. 1917-1967. Sbornik dokumentov za 50 let [Party and Government Decisions on Economic Issues. 1917-1967 Collection of Documents for 50 Years]. Moscow, Politizdat. Vol. 2: 1929-1940, pp. 250-254.

Shmidt, O.Yu. (Ed.). (1926-1947). Bolshaya sovetskaya entsiklopediya: [v 66 t.] [Great Soviet Encyclopedia: [in 66 vol.]]. Moscow, Sovetskaya entsiklopediya.

(1930). Sibirskiy kray. Statisticheskiy spravochnik [Siberian Region. Statistical Reference Book]. Novosibirsk, 804 p.

Sokolov, A.K. (2000). Sovetskaya politika v oblasti motivatsii i stimulirovaniya truda (1917 seredina 1930) [Soviet Policy in the Field of Motivation and Stimulation of Labor (1917 mid-1930s)]. In Ekonomicheskaya istoriya. Obozrenie. Moscow, Izd-vo Moskovskogo un-ta. Iss. 4, pp. 39-80.

(1925). Statisticheskiy obzor deyatel'nosti mestnykh administrativnykh organov NKVD [Statistical Overview of the Activities of Local Administrative Bodies of the NKVD]. Moscow, Iss. 4-5.

(1926). Statisticheskiy obzor deyatel'nosti mestnykh administrativnykh organov NKVD [Statistical Overview of the Activities of Local Administrative Bodies of the NKVD]. Moscow, Iss. 6.

(1927). Statisticheskiy obzor deyatel'nosti mestnykh administrativnykh organov NKVD [Statistical Overview of the Activities of Local Administrative Bodies of the NKVD]. Moscow, Iss. 7.

Uglanov, N. (1930). Rost kadrov rabochego klassa, izzhitie bezrabotitsy i snabzhenie sotsialisticheskogo stroitel'stva rabochey siloy [Growth of the Cadres of the Working Class, the Elimination of Unemployment and the Supply of Socialist Construction with Labor]. In Trud $v$ SSSR: sb. st. $k$ XVI part. s'ezdu / Narkomat truda SSSR. Moscow, Gostrudizdat. 183 p.

Статья поступила в редакцию 04.11.2021 г. 